\title{
Bringing GPU Accelerated Computing and Deep Learning to the Classroom
}

\author{
Joseph Bungo \\ NVIDIA Corporation \\ Austin, Texas \\ jbungo@nvidia.com
}

\author{
Daniel Wong \\ University of California, Riverside \\ Riverside, California \\ danwong@ucr.edu
}

\begin{abstract}
The call for accelerated computing and data science skills is soaring, and classrooms are on the front lines of feeding the demand. The NVIDIA Deep Learning Institute (DLI) offers handson training in AI, accelerated computing, and accelerated data science. Developers, data scientists, educators, researchers, and students can get practical experience powered by GPUs in the cloud. DLI Teaching Kits are complete course solutions that lower the barrier of incorporating AI and GPU computing in the classroom. The DLI University Ambassador Program enables qualified educators to teach DLI workshops, at no cost, across campuses and academic conferences to faculty, students, and researchers. DLI workshops offer student certification that demonstrates subject matter competency and supports career growth. Join NVIDIA's higher education leadership and leading adopters from academia to learn how to get involved in these programs.
\end{abstract}

By attending this talk, you will learn:

- How educators can access Teaching Kits with curriculum materials in accelerated computing, Deep Learning, and robotics.

- How to access free online training, certification, and cloud access to GPUs for teachers and students.

- An overview of the NVIDIA DLI and University Ambassador Program.

- How the Ambassador Program fits into larger programs that support teaching.

- $\quad$ Real examples of leading academics leveraging Teaching Kits and Ambassador workshops in the classroom.

\section{Keywords}

Hands-on learning, Training, HPC education, Deep learning, Machine learning, Artificial intelligence, GPU, Data science, Parallel computing, Accelerated computing
Permission to make digital or hard copies of all or part of this work for personal or classroom use is granted without fee provided that copies are not made or distributed for profit or commercial advantage and that copies bear this notice and the full citation on the first page. To copy otherwise, or republish, to post on servers or to redistribute to lists, requires prior specific permission and/or a fee. Copyright @JOCSE, a supported publication of the Shodor Education Foundation Inc.

(C) 2021 Journal of Computational Science Education DOI: https://doi.org/10.22369/issn.2153-4136/12/2/4 